\title{
Revista Brasileira de Enfermagem REBEn \\ Situações significativas no espaço-contexto da hemodiálise: o que dizem os usuários de um serviço?
}

\author{
Significant situations in the space and context of hemodialysis: what do users say about \\ Situaciones significativas en el espacio-contexto de hemodiálisis: que dicen los usuarios \\ de un servicio?
}

\section{Vanusa Pietrovski RESUMO}

Enfermeira. Mestre em Enfermagem pelo PPG/ENF-UFRGS. Enfermeira da Unidade de Terapia Renal de Pato Branco, PR.

\section{Clarice Maria Dall'Agnol}

Doutora em Enfermagem. Docente do Departamento de Assistência e Orientação Profissional da Escola de Enfermagem da UFRGS (DAOP/EENF-UFRGS), Porto

Alegre, RS. Orientadora do Estudo.

Este conteúdo deriva da Dissertação de Mestrado desenvolvida no Programa de Pós-Graduação da Escola de Enfermagem da Universidade Federal do Rio Grande de Enfermagem da Universidade Federal do Rio Grande espaço de hemodiálise na ótica de usuários com insuficiência renal crônica".

Estudo de abordagem qualitativa realizado em uma clínica de hemodiálise, no interior do Paraná, com pacientes em tratamento hemodialítico. 0 objetivo consistiu em conhecer situações significativas para 0 paciente renal crônico vivenciadas no espaço-contexto de hemodiálise. Os resultados apontaram dificuldades associadas ao processo de comunicação, falta de informações e o desconhecimento de aspectos que envolvem o tratamento. Ficou patente a atribuição de importância à família, a relação com os demais usuários e com os membros da equipe de saúde, como forma de contribuir para o processo de recuperação e de adaptação, em meio às adversidades impostas pela doença e tratamento. Aspectos relacionados à apresentação e estética do ambiente também emergiram como fatores que interferem na satisfação dos clientes.

Descritores: Unidades hospitalares de hemodiálise; Organização e administração; Serviços de saúde; Insuficiência renal crônica.

\section{ABSTRACT}

A qualitative study performed at a hemodialysis clinic in the interior of Paraná. Semi-structured interviews were used to look at significant situations for chronic renal patients, experienced in the space and context of hemodialytic treatment. The results indicated difficulties associated with the communication process, causing discomfort and a feeling of helplessness, especially at the beginning of the treatment. It was shown that importance was assigned to the family, to the relationship with the other service users and with the members of the health care team, as a way of contributing to the recovery and adaptation process, amidst the adversities imposed by the disease and treatment. Aspects related to the presentation, esthetics and cleanliness of the environment also emerged as factors that interfere in client satisfaction. Descriptors: Hemodialysis units, hospital; Organization and administration; Health services; Kidney failure, chronic.

\section{RESUMEN}

Estudio de abordaje cualitativo realizado en una clínica de hemodiálisis, en el interior del estado de Paraná, Brasil. A través de entrevistas semiestructuradas, nos propusimos a conocer situaciones significativas para los pacientes renales crónicos, vivenciadas en el espacio-contexto del tratamiento hemodialítico. Los resultados apuntaron a dificultades asociadas al proceso de comunicación, generando incómodo y sensación de desamparo, principalmente en el comienzo del tratamiento. Resultó clara la atribución de importancia a la familia, a la relación con los otros usuarios del servicio y con los miembros del equipo de salud, como forma de contribuir al proceso de recuperación y de adaptación, en medio no solo a las adversidades que la enfermedad y el tratamiento imponen. Aspectos relacionados a la presentación, estética e higienización del ambiente también han sido mencionadas como factores que interfieren en la satisfacción de los clientes.

Descriptores: Unidades de hemodiálisis en hospital; Organización y administración; Servicios de salud; Insuficiencia renal crónico.

Pietrovski V, Dall'Agnol CM. Situações significantes no espaço-contexto da hemodiálise: o que dizem os usuários de um serviço? Rev Bras Enferm 2006 set-out; 59(5): 630-5.

\section{INTRODUÇÃO}

O interesse em desenvolver um estudo sobre situações vivenciadas pelo paciente renal crônico em hemodiálise decorreu de observações surgidas ao longo da trajetória profissional de uma das autoras, em uma clínica de hemodiálise, que vinha presenciando queixas dos usuários a respeito do tratamento. Este era apontado como sendo demasiadamente técnico em razão do aparato instrumental utilizado, podendo-se

Submissão: $11 / 01 / 2006$

Aprovação: 13/05/2006 
exemplificar o emprego de filtros, alarmes e equipamentos sofisticados. Por outro lado, a própria condição da doença crônica impõe aos pacientes a necessidade de confiar suas vidas a uma máquina e à equipe que presta cuidados. No entanto, por parte da equipe de saúde desse setor, havia o entendimento de que uma assistência ideal estava sendo implementada, isto é, no sentido de que estava sendo oferecido o melhor aos usuários do serviço.

Em meio a tal contradição, tornou-se imperativo questionar: o melhor planejamento, sob o ponto de vista da equipe, corresponde às principais necessidades dos usuários? Como e em que medida os usuários têm participado desse processo? Aessas questões, agrega-se ainda outra, bastante instigante: "a ênfase no tratamento supervisionado não indicaria, de parte do discurso sanitário, uma tendência para infantilizar as pessoas? (1)" Diante destas indagações, buscou-se conhecer a experiência do paciente renal crônico, elencando situações que tivessem sido marcantes, positivas e/ou negativas, favoráveis e/ou desfavoráveis e, ainda, aquelas que vinham se constituindo como fator de satisfação e/ou de insatisfação durante o tratamento dialítico. Norteou-se pelo propósito de fornecer subsídios que contribuam para a (re)organização do serviço e da qualificação da assistência, visando beneficios, tanto para os indivíduos em condições crônicas como para a equipe que atua na prestação desse atendimento.

Um fator importante a ser considerado é o número de pacientes renais crônicos que necessitam de diálise para sobreviver. No Brasil, de acordo como Censo da Sociedade Brasileira de Nefrologia, 59.153 pessoas encontramse nesta situação, sendo que, deste total, 52.794 pacientes são submetidos ao tratamento de hemodiálise ${ }^{(2)}$. Outro aspecto, também levado em consideração, é o fato de que no Brasil e, principalmente na região Sul, nas últimas décadas, houve uma diminuição dos índices de morbimortalidade por doenças infecciosas e um aumento progressivo de doenças crônicas ${ }^{(3,4)}$.

\section{METODOLOGIA}

Estudo de abordagem qualitativa realizado em uma clínica de hemodiálise, no interior do Paraná. Este serviço funciona desde 1982, desenvolvendo atividades de clínica médica e nefrologia. De natureza privada, intra-hospitalar, conta com uma área física de $600 \mathrm{~m}^{2}$, cuja estrutura segue os padrões e normas regidas pela Resolução da Diretoria Colegiada ${ }^{(5)}$. A Unidade atende 16 pacientes por período, de segunda-feira a sábado, em três turnos. Atualmente dialisa 82 pacientes sendo que 78 procedem de demandas do Sistema Único de Saúde (SUS) e 04 derivam de convênios particulares. Aequipe é composta por dois médicos nefrologistas, duas enfermeiras e onze técnicos em enfermagem.

A coleta de dados ocorreu no período entre setembro a novembro de 2003, mediante Entrevistas Semi-Estruturadas com pacientes renais crônicos que vinham se submetendo ao tratamento de hemodiálise, nesse período. As entrevistas, gravadas em áudio, ocorriam antes de os pacientes iniciarem a sessão de hemodiálise, em uma sala nas dependências da Clínica, com total privacidade e silêncio. Solicitava-se o relato de algum(ns) fato(s) que tivesse (m) sido marcante(s) no espaço de hemodiálise, não importando se a experiência tivesse sido positiva ou negativa, boa ou ruim.

A seleção dos sujeitos ocorreu por meio de sorteio aleatório simples, a partir da listagem diária de pacientes e, tendo-se adotado o critério de saturação dos dados ${ }^{(6)}$, foram realizadas quinze entrevistas, transcritas na íntegra. Para a análise das informações recorreu-se à Técnica de Análise de Conteúdo, a qual possibilita uma descrição objetiva dos discursos, para posterior interpretação $0^{(7)}$.

Para o desenvolvimento da investigação, pautou-se na Resolução n 196 , de 10 de outubro de 1996, que dispõe sobre as Diretrizes e Normas Regulamentadoras de Pesquisa com Seres Humanos, publicada pelo Conselho Nacional de Saúde ${ }^{(8)}$ e somente deu-se início à coleta de dados após a homologação do projeto pelo Comitê de Ética em Pesquisa (CEP) da Universidade Federal do Rio Grande do Sul (UFRGS), registrado sob o número de 2003206. Nas entrevistas, adotou-se o Termo de Consentimento
Livre e Informado, em duas vias, uma destinada ao informante e outra à pesquisadora. No documento, constou explicitamente sobre os objetivos, método e possíveis benefícios do estudo, bem como sobre as formas de contato com a instituição de origem - UFRGS - sendo assegurada a livre participação, sem que nenhuma influência incorresse no tratamento a que os sujeitos vinham se submetendo. Para preservar o seu anonimato, eles foram identificados por um código: U1, U2, U3 (...) e assim sucessivamente.

\section{RESULTADOS E DISCUSSÃO}

O tratamento do material resultou em quatro categorias de maior relevância: início do tratamento, possibilidade de vida, estar com o(s) outro(s) e organização do ambiente físico, conforme é apresentado a seguir.

\subsection{Início do tratamento}

O impacto causado pelo início do tratamento, resultante da falta de preparo e orientação prévia, foi uma tônica nos relatos. Isso remete a pensar sobre a importância do acolhimento ao paciente renal crônico, mediante à nova condição que a doença lhe impõe, quando o mesmo passa a depender do tratamento dialítico. Acolhimento recai na humanização do atendimento que, por sua vez, pressupõe a garantia de acesso a todas as pessoas. Diz respeito, ainda, à escuta do problema de saúde do usuário, de forma qualificada e resolutiva(9). Neste estudo, ficou demarcado que há lacunas no processo de acolhimento, em se tratando dos primeiros contatos com o tratamento. Para os usuários do serviço, que se sentem surpreendidos pela nova condição a que se vêem submetidos, há uma carência de orientação prévia, já que pouco ou quase nada lhes é informado, provocando uma sensação de desamparo:

Quando eu comecei a fazer hemodiálise foi o que me marcou mesmo porque eu não tinha idéia do que era, não tinha nenhum conhecimento e logo já fui sendo cortada, colocando cateter (U1).

Quando eu comecei a fazer hemodiálise eu não sabia como era, não sabia como ia ser, ninguém tinha me explicado nada (U 7).

A partir dessas colocações, pode-se intuir que a sessão de hemodiálise é uma possibilidade para a equipe de saúde interagir com o paciente renal crônico e auxiliá-lo no suprimento de suas necessidades. No tempo de permanência na clínica, várias ações da equipe de saúde podem reverter-se em um processo educativo em que, por exemplo, se possa dialogar sobre dieta, medicações, com esclarecimento de dúvidas, orientações sobre esportes e lazer, enfim, visando criar condições satisfatórias para o bem-estar do usuário do serviço.

Nas falas, percebe-se que 0 atendimento das necessidades físicas é colocado em primeiro plano de tal forma que gera importantes lacunas na prestação do cuidado e estas derivam de falhas na comunicação com 0 cliente, como foi dito:

O começo foi difícil, eu fiquei quase doida. Eu não estava preparada quando comecei a dialisar. Quando eu entrei na sala de hemodiálise, minha nossa. Eu acho que deveriam ter me explicado como era e o que ia acontecer, eu não sabia nada, nada. Simplesmente me colocaram na máquina. Acho que eu deveria ter tido uma orientação, eu ia saber de tudo (U 8).

Há necessidade de uma intervenção educativa e de suporte psicológico, durante a fase inicial do tratamento. Um apoio social pode prevenir ou servir e ser utilizado como defesa emocional das conseqüências psicológicas negativas, durante o declínio da função física ${ }^{(10)}$.

\subsection{Possibilidade de vida}

A sensação de obrigatoriedade em aceitar o tratamento, como única forma de manutenção da vida, e a fé em Deus, como fator de auxílio para enfrentar 
essa situação, foram questões incisivas na fala dos informantes. Para o doente com insuficiência renal crônica, o tratamento hemodialítico é necessário, provocando uma realidade que não há como ser diferente, não existe opção, ele necessita do tratamento. Fica claro que existem situações na vida que independem da vontade e fogem ao controle do indivíduo. A adaptação não acontece em um passe de mágica, é um processo complexo que mobiliza estruturas individuais:

Eu não aceitava e acho que acostumarninguém vai acostumar, porque é muito difícil, mas é uma maneira da gente continuar sobrevivendo (U 1).

Eu acho que ninguém aceita. Porque não vi ninguém que entrou aqui depois de mim que dissesse que é bom. Mas é uma coisa que eu preciso e dependo para viver. É uma coisa que, hoje, é necessária para minha vida (U 3).

Por analogia a alguns achados na literatura ${ }^{(11)}$, estes depoimentos retratam explicitamente os estágios de enfrentamento de pacientes que se encontram em fase terminal de uma doença, ao tomarem conhecimento da sua condição, traduzindo-se em negação, raiva, barganha, depressão e aceitação. Anegação é uma defesa temporária, sendo logo substituída por uma aceitação parcial. A esperança mantém-se presente em todas as fases do processo de adaptação, e é a forma encontrada pelos clientes para ter forças e continuarem vivendo em situações adversas. Por um lado, os pacientes vislumbram a possibilidade de melhora e, por outro, tomam consciência da necessidade da convivência com tratamentos, intervenções e cuidados que geralmente são obrigatórios e de longa duração $0^{(12)}$. Esse quadro é ilustrado na fala de U 11:

Fazer hemodiálise foi bom porque eu melhorei, estava ruim e melhorei bem. Só que eu achei que era só por uns dias e que eu ia ficar boa, ai o Dr. me explicou que o meu rim não funcionava mais, daí foi difícil (U 11).

A doença renal crônica é vista pelos pacientes como um fator de profundas mudanças em suas vidas. 0 mesmo também se observa no estudo com pacientes oncológicos que percebem a doença como praticamente fatal, produzindo profundas repercussões na vida do indivíduo que experiencia este diagnóstico e as mesmas poderão ser positivas ou negativas, uma vez que 0 modo como cada um percebe e enfrenta a doença, está associado à forma como ele constrói seu processo de viver ${ }^{(13)}$. Mediante as várias dimensões que estão implicadas, espera-se da equipe de saúde que não se restrinja apenas ao uso de saberes acadêmicos, focados na perspectiva do modelo clínico de intervenção, mas que assuma uma conduta capaz de contextualizar 0 atendimento de necessidades que se insurgem como prioritárias para 0 paciente renal crônico. Convém destacar que este se depara com inúmeras perdas, geralmente o emprego, o vigor físico, tendo que se habituar com restrições alimentares e comparecer à clínica para dialisar três vezes por semana. Além disso, enfrenta uma lista de espera por um transplante renal. Acerca dessas questões a equipe de saúde deve estar preparada, dialogando entre si e com os clientes para, conjuntamente, estabelecer planos de ação a curto, médio e longo prazos, que oportunizem um satisfatório enfrentamento da doença e do tratamento.

Para os pacientes crônicos não há muitas escolhas na resolutividade de sua condição. Eles se vêem dependentes do tratamento dialítico ou, então, da submissão a um transplante renal. Aesperança no transplante ilumina-se na perspectiva de ter mais liberdade, única alternativa para não mais depender do tratamento hemodialítico. Por outro lado, situações que dizem respeito à procedência e doação do rim - por pessoas da família ou não - desencadeiam angústias.

Isso emergiu nas entrevistas:

A hemodiálise é desconfortável porque você não pode viajar, não pode ficar fora. Por isso eu digo que transplantaré melhor porque dai a gente tem liberdade, pode sair (U9)

O transplante, sinceramente eu gostaria muito e quero um dia, e tenho fé que eu vou conseguir. Não que a hemodiálise seja tão terrivel assim, mas eu acho que no transplante as dificuldades são bem menores. Com o transplante se tem mais liberdade. Eu acho que posso melhorar bastante (U 15).

Os portadores de doença renal crônica vêem no transplante renal a única forma de realmente ter uma vida plena, entendendo por vida plena o retorno a suas atividades anteriores, tendo uma vida "normal", como foi enfatizado.

$\mathrm{Na}$ expectativa de realizar o transplante, os pacientes renais vivem a angústia de aguardar um possível doador, seja no seio da família ou por meio de um doador cadáver. Mas, em nome de tal acesso, munem-se de forças para todo tipo de enfrentamento, em meio à espera até que se efetive a localização de um órgão compatível, a definição quanto a doador vivo ou cadáver, a legalização de documentos. 0 decreto-Lei n ${ }^{0} 2268$, de julho de 1997, artigo $2^{\circ}$, criou e organizou o Sistema Nacional de Transplante (SNT), responsável pela normatização da captação e distribuição de tecidos de órgãos e de partes do corpo para finalidades terapêuticas. OSNT tem como âmbito de intervenção as atividades de conhecimento de morte encefálica verificada em qualquer ponto do território nacional e a determinação do destino dos tecidos, órgãos e partes retiradas ${ }^{(14)}$.

Doação de órgãos ainda é um assunto de pouco domínio público, terreno fértil para a proliferação de mitos, tabus e mal-entendidos, na população. Até mesmo a equipe de saúde não está suficientemente esclarecida para auxiliar nestas questões ${ }^{(15)}$. Isso leva a refletir e questionar: qual o preparo dos profissionais da saúde para lidarem com estas questões? Que informações circulam nesse meio e como são apresentadas aos pacientes eaos respectivos / possíveis doadores?

\subsection{Estar com o(s) outro(s)}

A importância da família no acompanhamento do tratamento do paciente renal crônico evidenciou ser um fator que contribui de forma efetiva para a adaptação do hemodialisado. Devido às restrições impostas pela doença crônica e pelo tratamento, faz-se importante o apoio familiar e social como forma de incentivo na sua trajetória ${ }^{(16)}$

É importante você ter apoio da família, e eu tenho dos meus filhos, do meu marido (U6).

Com o apoio muito grande da minha família fui encarando a hemodiálise. Eu acho que se não fosse a minha família, não sei (...) (U 3).

Através dos relatos de $U 1$ e $U 9$ observa-se que nem sempre se inclui a família quando se trata do paciente, deixando-as muitas vezes sem orientação e incentivo na participação do tratamento. É preciso esclarecer sobre o tratamento, procedimentos, etc. como forma de minimizar as angústias dos familiares e também para que esses, cientes do que está acontecendo com seu familiar, possam efetivamente servir de apoio.

Meu filho chegou para me visitar e em vez de ele me consolar, eu tive que consolar ele. Ele virou num choro quando me viu lá [na hemodiálise], com cateter e tudo, não sabia o que era aquilo (U 1).

Quando eu comecei a dialisar, que eu coloquei o cateter, eu queria encorajar a minha família, entende? Porque a P. chorava muito e eu queria encorajar eles (U 9).

É importante salientar que a família pode servir como fonte para o enfrentamento da doença e de suas conseqüências, uma vez que ela faz parte do contexto no qual o indivíduo está inserido. Muitas vezes, a experiência do 
adoecimento leva ao fortalecimento das relações familiares.

A convivência com os demais usuários, na clínica, surgiu nas falas com uma dupla conotação: de um lado, foram apontadas dificuldades de relacionamento e até mesmo de falta de privacidade, em presença tão próxima do(s) outro(s) pacientes; por outro lado, vínculos de amizade e de mútuo reforço são constituídos no seio desta convivência, pois é o próprio tratamento, em dias alternados, que proporciona momentos de reencontros face-a-face que fortalecem as relações. O sentimento de ambivalência, em presença dos outros pacientes, ficou bem demarcado:

Eu tenho os pacientes, os outros meus colegas, todos como irmãos. Eu quero bem todos eles. Tem uns que não são muito de conversar, mais a gente respeita, porque a gente conta tudo um para o outro, tenho todos como uma família (U 9).

A nossa turma é assim, boa. Todos assim mais ou menos (...) tem uns que às vezes incomodam um pouco. Se a gente não gosta das brincadeiras tem que ficar quieto e pronto. Tem que aceitar (U 13).

Aqui é uma sala de hemodiálise e como eu gosto de respeitar os outros eu também gosto de ser respeitada. Porque nós já tivemos uma encrenca no primeiro dia, eu e o (...), até hoje ele não me engole por causa disso (U8).

O apoio multiprofissional é fundamental para que o indivíduo e sua família possam assimilar e responder melhor à vivência da doença crônica e ao tratamento ${ }^{(17)}$, tanto que foi comentado:

Eu sempre fui bem atendida, de todos os lados, tanto da enfermagem como dos médicos, como das outras pessoas que trabalham aqui. Sempre me dão atenção no que eu preciso (U 13).

Em momento algum eu posso dizer que fui mal atendido, ao contrário, eu sempre fui bem atendido. Esse relacionamento aconchegante entre a equipe e o paciente me deu segurança total. (U 5)

Os depoimentos demonstram a importância da equipe de saúde para os usuários na prestação de um atendimento efetivo, contribuindo para proporcionar segurança, na medida em que há um real investimento nas relações interpessoais. Há necessidade de uma atenção em saúde em uma lógica acolhedora, a qual se destaca como sendo um espaço intercessor trabalhador/ usuário que se abre para um processo de escutas dos problemas, para troca de informações, para um mútuo reconhecimento de direitos e deveres e para um processo de decisões que pode possibilitar intervenções pertinentes e/ou eficazes, em torno das necessidades dos usuários ${ }^{(9)}$. Mas, paralelamente aos comentários que referem o bom atendimento, houve outras sinalizações:

(...) às vezes se a gente chama e elas [membros da equipe de enfermagem] demoram e se você chama é porque precisa na hora. (U 7)

A hora que ela vai puncionar [punção venosa], ela não tem atenção de ficar olhando, ela é desatenta, conversa (...). Outra coisa, tem dias que elas [membros da equipe de enfermagem] não observam o quadro de avisos, eu acho que é uma obrigação delas lerem o quadro. (U 8)

Além do que já se mencionou, houve destaque à interação que se estabelece entre o paciente renal crônico e a equipe de saúde, não apenas em vigência do tempo de permanência na clínica demandado pela hemodiálise, mas também por tratar-se de um procedimento bastante especializado que é de domínio de uma equipe igualmente especializada. Em muitos momentos do tratamento, esta condição forja uma inevitável relação de dependência por parte do paciente para com os profissionais que sistematicamente 0 atendem. No entanto, concebe-se que isto seja plausível em se tratando do saber-fazer no âmbito tecnológico do cuidado em hemodiálise. Porém, se tal pressuposto for transposto para outras esferas do cuidado, como as que transitam no processo interativo - inclusive durante a realização de procedimentos técnicos - o risco é de imprimir a marca de um modelo vertical, hierarquizado, alheio a uma proposição dialogada, de co-gestão de coletivos.

\subsection{Organização do ambiente físico}

O procedimento de hemodiálise, embora seja realizado em serviços ambulatoriais, é considerado de alta complexidade. Para um doente fazer uma sessão de hemodiálise é preciso prever e dispor de espaço físico adequado, equipamento tecnológico específico, tratamento especifico da água, materiais descartáveis, medicações, equipamentos de urgência, entre outras condições. Apesar de todo o aparato tecnológico-instrumental que envolve o tratamento hemodialítico, os participantes desta pesquisa não manifestaram preocupação com tais questões que não foram sequer mencionadas. Nos depoimentos, surgiu em destaque o conforto ambiental:

(...) aqui o conforto para o paciente é coisa sem comentários, desde as acomodações, tudo [...] (U 5).

Eu hoje faço hemodiálise porque tenho que fazer, mas a gente está aqui numa boa, dormindo, vendo televisão, comendo (...) (U 15).

Percebe-se que a importância que os usuários dão ao ambiente está relacionada ao conforto que o serviço proporciona em termos de hotelaria e não o que diz respeito aos procedimentos técnicos, máquinas de hemodiálise ou outros equipamentos e materiais. Em diversos depoimentos surgiram queixas relacionadas ao barulho na sala de hemodiálise, ao ambiente considerado muito frio - eà falta de lazer durante o tempo em que se submetem ao tratamento hemodialítico:

Há também uma coisa, quando vão abrir uma gaveta, uma porta, sabe, dão aquela batida que dói nos ouvidos da gente. Às vezes tem algum paciente dormindo que chega até se assustar com essas batidas (U 2).

Na hemodiálise eu tento dormir, mas eu consigo dormir uma hora e nessa uma hora a agitação é muito grande, não se preocupa, na hora de bater uma gaveta, fazem barulho, de repente a gente ali leva aquele susto, muitas vezes não controla nem o braço da fístula com o susto que leva. Então, às vezes, na correria, não tem muito essa preocupação de fazer barulho e acordar alguém (U 14).

O significado que as pessoas atribuem aos acontecimentos que se sucedem em suas vidas difere de um indivíduo para o outro, de um momento para o outro, de um dia para o outro ${ }^{(18)}$, sendo importante que os profissionais de saúde oportunizem a inclusão do próprio usuário no planejamento de ações que possam da melhor forma satisfazer suas necessidades. Isto começa pela escuta, pela busca de entendimento do que um e outro percebem como necessidade e satisfação, cujo diálogo possivelmente não esteja ocorrendo, haja vista que até mesmo a regulação da temperatura ambiental foi trazida como um problema a ser equacionado. Os usuários referiram-se ao ambiente muito frio na sala de hemodiálise devido ao ar condicionado, questionando se o conforto é para os pacientes em tratamento hemodialítico ou para a equipe de enfermagem:

(...) como o ar condicionado, tem muita gente que não gosta e não falam. 0 ar condicionado, este do corredor é muito gelado (...) a hora que o pessoal pára, o ambiente vai começar a esfriar porque não abre e fecha mais a porta, então são coisas assim. Eu entendo o lado delas, cheias de roupas, pra elas fica calor mas pra nós é frio (U 14).

Uma coisa que eu não gosto é esse ar condicionado, é muito frio, eu tenho 


$$
\text { uma raiva }(\ldots)(\cup 4) \text {. }
$$

O que é visto pela equipe de saúde como boa estrutura e ambiente adequado, não é percebido da mesma forma pelos usuários do serviço. Nem sempre o que é preconizado e instituído formalmente, visando contemplar normas de qualidade, atende às reais necessidades dos clientes e, muitas vezes, os usuários colocam-se em posição de subordinação diante dos profissionais, pois deles depende seu tratamento e, com receio de que este seja comprometido, acabam calando-se diante de certos desconfortos.

Preencher o tempo durante as sessões de hemodiálise também foi um aspecto trazido para a pauta das reivindicações:

Aqui são quatro horas que tem que ficar e tem que ficar, daí a gente não tem alguma coisa para se ocupar. Se não conseguir dormir e na televisão não estiver passando nada de bom, a gente fica quatro horas olhando para a parede, então uma falta é isso aí, ter alguma coisa que te ocupe o espaço (...) vendo alguma coisa diferente, se instruindo (...) então uma ocupação seria bom (U 14).

(...) eu não paro quieto e ficar quatro horas preso ali, eu tenho que estar aqui e tenho que preencher meu tempo (U5).

Embora os profissionais não devam abdicar da presteza, segurança e habilidade técnica, como condições indispensáveis ao cuidado especializado, eles também devem estar atentos a outras dimensões do ser humano e em constante busca de estratégias para supri-las. Conforto emocional, diálogo, preenchimento criativo do tempo e atenção são esferas que indubitavelmente convergem para o cuidado humanizado ao paciente renal crônico, francamente retratado nas verbalizações dos sujeitos participantes.

As condições de higienização do ambiente igualmente permearam os relatos, com críticas revezadas ao serviço de limpeza da clínica - campo de pesquisa - não havendo referência direta à ambiência da hemodiálise propriamente dita, porém à sala de espera, aos vestiários e aos sanitários:

Ea limpeza, deixa muito a desejar. Acho que às vezes o papel do banheiro é tirado uma vez por semana. Os cantos sujos no vestiário, no banheiro, parece que ficam semanas sem serem limpos (U 7).

A única coisa é a limpeza, porque eu acho que fica só passando pelo meio, os cantos a gente vê que está sujo, o banheiro tem dias que não dá para entrar é um lugar que todos usam, os pacientes, os acompanhantes, então não dá (U 12).

Além dos profissionais diretamente envolvidos na prestação do atendimento ao cliente, outros trabalhadores como os da limpeza desenvolvem atividades bastante importantes para que o cuidado institucional se efetive, garantindo um ambiente seguro, não agressivo, zelando para que se estabeleçam interações agradáveis e vitalizadoras ${ }^{(19)}$.

\section{CONSIDERAÇÕES FINAIS}

Aescuta de pacientes renais crônicos, em tratamento hemodialítico, forneceu importantes subsídios para que se repense aspectos da dinâmica organizacional em um ambiente de hemodiálise, principalmente para que as equipes reconheçam, cada vez mais, que o cuidado não pode ficar circunscrito a um rim doente. É preciso perceber a magnitude da presença de um ser humano que almeja ver atendidas ou, pelo menos, ser compreendido em suas expectativas e, como condição primeira, ser respeitado em sua individualidade. Para tanto, é necessário ampliar o leque de atenção e extrapolar a fronteira da sofisticação tecnológicae do aparato instrumental que, mesmo sendo importantes e indispensáveis no tratamento hemodialítico, são insuficientes para suprir as necessidades do um ser humano que está sendo cuidado.

Com a pesquisa, ratificou-se o quanto é importante considerar as várias dimensões da natureza humana, na tentativa de obter melhores resultadose que atendam as reais necessidades dos usuários de serviços de hemodiálise. Pensar em estratégias que dêem suporte para o paciente renal crônico no enfrentamento de sua condição é um desafio constante para os profissionais da saúde. Alguns dos encaminhamentos concretos, pelo menos que possam contribuir com esse campo de pesquisa, seria a implantação de um sistema de Ouvidoria e mesmo a coleta de opiniões por meio de caixa de sugestões, uma medida simples, mas que pode ser estratégica. Outra possibilidade consiste em sistematizar grupos de sala de espera, visando integrar usuários e equipe multiprofissional com vistas a processos educativos que promovam planejamentos e ações compartilhadas.

Os resultados do estudo oportunizaram discussões que vão além do desempenho técnico. Enfim, de um ambiente de hemodiálise se espera que haja conscientização e um franco reconhecimento do papel social em nome de um atendimento mais humanizado ao paciente renal crônico.

\section{REFERÊNCIAS}

1. Campos GWS. Saúde paidéia. São Paulo (SP): HUCITEC; 2003.

2. Sociedade Brasileira de Nefrologia. Censo dos Centros de Diálise do Brasil. São Paulo, 2004. Disponível em: URL: http:// www.sbn.org.br.Censo/censo02htm

3. Trentini M, Silva DGV, Leiman AH. Mudanças no estilo de vida enfrentadas por pacientes em condições crônicas de saúde. Rev Gaúcha Enferm 1990; 11(1): 18-28.

4. Brasil. Ministério da Saúde. Sistema Único de Saúde. Anuário estatístico de saúde do Brasil. Brasília (DF): Ministério da Saúde; 2001.

5. Brasil. Ministério da Saúde. Resolução RDC $n^{0} 154$. Regulamento técnico de funcionamento dos serviços de diálise - Brasília (DF): Ministério da Saúde; 2004.

6. Denzin NK, Lincoln YS. Handbook of qualitative research. $3^{\text {rd }}$ ed. Thosuand Oaks (CA): SAGE; 2005.

7. Bardin L. Análise de conteúdo. Lisboa (POR): Edições 70; 1977.

8. Brasil. Ministério da Saúde. Conselho Nacional de Saúde. Resolução no 196/96. Diretrizes e normas regulamentadoras sobre pesquisa envolvendo seres humanos. Diário Oficial da República Federativa do Brasil, 10 out. 1996.
9. Merhy EE. Em busca do tempo perdido: a micropolítica do trabalho vivo em saúde. In: Merhy EE, Nocko $\mathrm{H}$. Agir em saúde: um desafio para o público. $2^{\text {a }}$ ed. São Paulo (SP): HUCITEC; 2002.

10. Shidler NR, Peterson RA, Kimmel PL. Quality of life and psychosocial relationships in patient with chronic renal insufficiency. Am J Kidney Dis 1998; 32(4): 557-66.

11. Kübler-Ross E. Sobre a morte e o morrer. São Paulo (SP): Martins Fontes; 2002.

12. Lima AF, Gualda DMR. Reflexão sobre a qualidade de vida do cliente renal crônico submetido a hemodiálise. Nursing 2000; 3(30): 20-3.

13. Rzebik C, Dall'Agnol CM. (Re)descobrindo a vida apesar do câncer. Rev Gaúcha Enferm 2000; 21(esp): 84-100.

14. Brasil. Ministério da Saúde. Sistema Nacional de Transplantes. Decreto nº 2.268 de 01 de julho de 1997. Brasília (DF): Ministério da Saúde; 1997.

15. Almeida KC. Doação de órgãos e bioética: construindo uma interface. Rev Bras Enferm 2003; 56(1): 18-23. 
Situações significantes no espaço-contexto da hemodiálise: o que dizem os usuários de um serviço?

16. Gualda DMR. Humanização do processo de cuidar. In: Cianciarullo TI, Fugulin FMT, Andreoni S. A hemodiálise em questão: opção pela qualidade assistencial. São Paulo (SP): Ícone; 1998. p. 23-30.

17. Lima AFC. O significado da hemodiálise para o paciente renal crônico: a busca por uma melhor qualidade de vida (dissertação)
São Paulo (SP): Universidade de São Paulo; 2000.

18. Siqueira $\mathrm{HCH}$. As interconexões dos serviços no trabalho hospitalar: um novo modo de pensar e agir (tese). Florianópolis (SC): Universidade Federal de Santa Catarina; 2001.

19. Silva RF, Erdmann AL. Ambiente do cuidado: dimensão ecológica. Texto \& Contexto Enf 2002; 11(3): 72-82. 